\title{
PROFILE OF CULTURAL HUMILITY IN COLLEGE STUDENTS
}

\author{
Muhamad Rifa'i Subhi ${ }^{1}$
}

\begin{abstract}
This study aims to describe the profile of cultural humility in the students. The scope of this study includes the positive characteristic characteristics, and negative characteristics reflecting superiority and making assumptions. The results of the study indicate that the profile of cultural humility in each student can not be separated from activities or activities in everyday life. This shows that cultural humility is an ability that is not automatically owned by individuals. A special development program is required for cultural humility to be mastered well by potential counselors. One of these is the personal humility development guidance program. Through the guidance, the program is expected to grow cultural humility which eventually can be obtained endpoint of cultural humility in the form of the character of flexibility or humility of the individual when interacting with others.
\end{abstract}

Keywords: Cultural Humility, Guidance and Counseling

JOMSIGN: Journal of Multicultural Studies in Guidance and Counseling

Website: http://ejournal.upi.edu/index.php/JOMSIGN

Permalink: http://ejournal.upi.edu/index.php/JOMSIGN/article/view/6314

How to cite (APA): Subhi, M., R. (2018). Profile of Cultural Humility in College Students. JOMSIGN: Journal of Multicultural Studies in Guidance and Counseling, 2(2), 148-159

This is an open-access article distributed under the terms of the Creative Commons Attribution 4.0 International License, which permits unrestricted use, distribution, and reproduction in any medium, provided the original work is properly cited.

\section{INTRODUCTION}

Multicultural problems in guidance and counseling services are something that cannot be avoided anymore. Some of them are the fact that there are different cultural, religious or social status backgrounds between counselor and counselee. This if not addressed properly there can be a bias that results in ineffective guidance and counseling services (Supriatna, 2014; Setyaputri, 2017). On the other hand, multicultural issues also have a large and strong influence in shaping the paradigm of guidance and counseling going forward, so that counselors' understanding of multicultural issues is one of the competencies that must be mastered well (Sanyata, 2013; Mufrihah, 2014).

Especially with the existence of cultural diversity in Indonesia which ultimately fostered multicultural societies. This further reinforces that

\footnotetext{
${ }^{1}$ Sekolah Tinggi Ilmu Tarbiyah (STIT) Pemalang; muhamadrifaisubhi@stitpemalang.ac.id
} 
multicultural problems cannot be avoided by counselors in carrying out their professional duties. The existence of cultural diversity has an impact on the emergence of cultural competence in the practice of guidance and counseling services, where multicultural complexity provides great benefits in formulating cultural competence as a process. This view asserts that counselors need to develop abilities or competencies in an ongoing manner of understanding the state of the counselee and the counselor himself.

Counselors come with their hopes, experiences, beliefs, communication styles, and attitudes towards the services they will obtain. Whereas counselors also bring their assumptions, experience with other counselees who have different cultural backgrounds, as well as their knowledge of solving problems in guidance and counseling. This fact needs to be considered carefully so that the guidance and counseling services provided can be effective in helping counselees. One of the abilities that can be mastered by counselors in overcoming this problem is to develop the ability of cultural humility.

Traditionally, humility is used to show a willingness to judge accurately about limitations on oneself, the ability to recognize gaps in knowledge, and openness to new ideas, contradictory information, and advice. In guidance and counseling, humility is more about recognizing the limitations of a cultural perspective to provide better services. The existence of such recognition makes it easy for counselors to be reflective and proactive about prejudices and assumptions of someone who might influence interactions with members of different cultures (Tangney, 2000; Pinto, 2007).

Two factors can lead the counselor to master cultural humility. The first is a lifetime commitment to continue to evaluate and self-critique (Tervalon \& Murray-Garcia, 1998). The first aspect suggests that the counselor's ability for cultural humility continues to develop and will never be finished. Therefore, counselors must be humble and flexible, dare to see themselves critically and want to learn more. Willingness to do this is an integral part of cultural humility aspects.

Second, cultural humility is the desire to correct power imbalances (Tervalon \& Murray-Garcia, 1998). Acknowledging that each counselee brings something different, helps the counselor assess each person. When the counselor interviews the counselee, the counselee is an expert in his own life, symptoms, and strengths. Counselors hold the knowledge that is not possessed by the counselee. However, the counselee also has an understanding outside the 
scope of the counselor. Both must collaborate and learn from each other for the best results.

Cultural humility is a subdomain of humility which involves one's ability to maintain interpersonal attitudes oriented to others, even under the pressure of cultural differences between counselee and counselor (Davis, DeBlaere, Cirleen, Owen, Jordan II, Hook, \& Tongeren, 2016). Cultural humility is different from cultural competence. This difference can be seen from eight characteristics. The first characteristic, view of culture. In this first feature, cultural humility has a cultural view of the uniqueness of each individual, not of the group. This is because cultural humility comes from a variety of different inputs on each uniqueness and can change according to the context that surrounds it.

The second characteristic, culture definition. In this second characteristic, what is meant by culture in cultural humility is a combination of ethnicity, race, age, income, education, sexual orientation, belief in each individual, and is not a minority of an ethnic or racial group. The third characteristic, traditions. In this third characteristic, cultural humility emphasizes that each individual follows the existing tradition, in contrast to cultural competence, who thinks that only minorities must follow the tradition. The fourth characteristic, context. In this fourth characteristic, cultural humility believes that there are differences in power between individuals that must be recognized and understood. The fifth characteristic, results. In this fifth feature, cultural humility emphasizes the existence of respect as a result of cultural humility. The sixth characteristic, focus. In this sixth characteristic, the thing that becomes the main focus in cultural humility is not only other people but also including yourself. The seventh feature, process. In this seventh characteristic, cultural humility is an ongoing life process, in contrast to cultural competence which highlights the differences that exist. While on the eighth characteristic, endpoint. In this eighth characteristic, the endpoint of cultural humility is the emergence of the character of flexibility or humility (humility) of individuals when interacting with others, not competence or expertise as the endpoint of cultural competence (Yeager \& Bauer-Wu, 2013).

This reduction shows that although cultural humility is different from cultural competence, cultural humility has a close relationship with culture (culture), where culture refers to a system that is understood together. This is expressed through habits, practices, and thoughts. So it is with counselors and 
counselors also have a different culture. Some things that are included in one's culture are age, level of education, ethnicity, geographical origin, gender, group history, language, life experience, religion, spiritual beliefs and practices, sexual orientation, and socioeconomic class.

Culture is learned and transmitted by certain community members or communities. It is dynamic and changes over time. Culture integrates various aspects of one's life and provides a framework for behaving or acting, but knowing one's culture does not mean that the counselor can predict the counselee's beliefs, values, or behavior. Therefore, a culture-oriented approach is needed as the best way to ensure that the guidance and counseling services provided are culturally safe, where cultural humility is an attitude towards understanding different cultures between counselor and counselee.

This approach emphasizes the interactive relationship between the counselor and the counselee. The counselor is more about asking questions than making assumptions about the counselee's problem and the counselor always tries to understand rather than informing him about solving the counselee's problem (Tervalon and Murray-Garcia, 1998). Through this approach, there is growing confidence and attitudes of counselors to avoid the practice of ineffective guidance and counseling services and the injustice of multicultural problems. Ross (2010) asserts that cultural humility has three focuses, namely knowledge, attitudes, and skills.

The statement from Ross was also strengthened from the results of Hook, Davis, Owen, Worthington \& Utsey (2013) which showed that the development of multicultural competencies in the fields of education, training, research, and practice was an important thing that had to be done. There are three main components in this regard, namely attitudes/beliefs, knowledge, and skills. This guide encourages experts to (a) develop an understanding of their cultural background and how their cultural background influences their attitudes, values, and beliefs; (b) developing understanding and knowledge of individual worldviews from diverse cultural backgrounds (knowledge), and (c) using appropriate cultural interventions (skills).

Cultural humility has an important role in education, especially for teachers in understanding the characteristics of their students. Building cultural humility is in line with the idea of a growth mindset where effective teachers believe in the growth of intelligence and talent, and they are fascinated by the learning process. (Tinkler \& Tinkler, 2016). This provides a great opportunity 
for counseling teachers or counselors at school to understand counselees or students they encounter while working at the school, especially when providing multicultural guidance and counseling services.

Cultural humility is closely related to the multicultural guidance and counseling process. First, counselors with high levels of cultural humility can do less counseling skills development than counselors with low levels of cultural humility, because of their increased sensitivity to the importance of diversity and respect for cultural differences. Second, when counselors encounter culturally diverse counselors, counselors with a high level of cultural humility can restore and repair relationships more easily than counselors with a low level of cultural humility, because they recognize their limitations in understanding and communicating respect for the cultural background of clients. (Hook, Farrell, Davis, DeBlaere, Tongeren, \& Utsey, 2016).

Furthermore, Hook, Davis, Owen, Worthington, and Utsey (2013) suggest that cultural humility is construction for understanding and developing abilities, which uses a process-oriented approach. Cultural humility is conceptualized as the ability to maintain interpersonal attitudes that are oriented towards others (or open to others) about aspects of cultural identity that are believed to be important to that person (Hook, Davis, Owen, Worthington and Utsey, 2013).

In contrast to cultural competence which implies that a counselor fully masters the culture - including customs and beliefs - the counselee is different from the counselor, cultural humility emphasizes the recognition that the counselor is not possible to know thoroughly about the counselee's culture. Cultural humility gives the counselor the skills to have openness in ways of thinking, acting and behaving to counselees who have different cultures, so there will be no bias. Through cultural humility, the counselor can be responsible for interactions with the counselee in addition to acknowledging or being sensitive to differences that exist (Levi, 2009). Cultural humility is an acknowledgment of one's limitations on a comprehensive understanding related to different cultures (Wear, 2008).

Thus, cultural humility is an important ability to be mastered by the counselor. Several things reinforce that cultural humility is important for the counselor to master. First, cultural humility has the meaning of not underestimating others. An understanding of various assumptions in a multicultural context is important, but the professional counselor's 
understanding of cultural differences can influence interactions in the guidance and counseling process (Miller, 2009).

Cultural humility is also an important first step in helping to correct the imbalance of power inherent in the relationship between counselor and counselee (Borkan, 2008). Starting a relationship or meeting based on the assumption that the counselee has knowledge and culture that is different from the counselor, and remains open-minded and still respects the counselee, greatly influences the success of the service to be provided. This is because cultural humility is a kind of reflective attention, which requires a lot of self-awareness and goes far beyond the knowledge of specific cultural details. In such cases, counselors must always be aware of the fact that extensive knowledge of a particular culture is not the same as assimilating themselves into the culture itself so that within the counselor must be aware of the differences that will exist between their perspectives and the perspective of the counselee who is a member of the culture different.

Based on the description above, it can be understood that cultural humility includes respectful, considerate, interested in learning more, and open-minded. Whereas the lack of cultural humility can lead to making assumptions about others (making assumptions about others), being a know-it-all (being knowledgeable), acting superior (acting superior/arrogant), and thinking one understands more than one does (think to have more understanding than it does). This is confirmed by the statements of Hook, Davis, Owen, Worthington \& Utsey (2013), which make some of these aspects a cultural humility factor. These factors are categorized into two factors, namely positive other-oriented characteristics, and negative characteristics reflecting superiority and making assumptions.

$\mathrm{n}$ other words, cultural humility is a process of self-reflection and discovery to build honest and trustworthy relationships. This relationship offers hope for counselors to understand and eliminate multiculturalism gaps or problems in the implementation of guidance and counseling services. This article presents a discussion of the cultural humility profile of students, as a first step in developing students' abilities or competencies related to the practice of multicultural counseling and guidance services. It is hoped that this study will become a reference in developing counseling programs for the personal development of students 'counselors' personal development. 


\section{METHOD}

This study uses analytic survey research, which is a cross-sectional survey which is a study that studies the dynamics of correlation between cause and effect factors. The survey uses a Cultural Humility Scale instrument that has been adapted and modified from the Cultural Humility Scale (CHS) and interviews. Participants in this study were 3 students, consisting of 2 women and 1 man.

The instrument used in this study is the result of adaptation and modification of the instrument developed by Hook, Davis, Owen, Worthington \& Utsey (2013). This instrument is known as the Cultural Humility Scale (CHS). CHS has 12 items with answer choices on a scale of 1-5 ( $1=$ strongly disagree; 5 = strongly agree) on 2 cultural humility factors. These factors are positive other-oriented characteristics, and negative characteristics reflect superiority and making assumptions. While the interview instrument was used as a form of verification of the 12 items in question.

The data obtained were analyzed descriptively. The level of cultural humility level is generally divided into three namely low (12-28), moderate (2944) and high (45-60). In terms of assessing the results of each factor of cultural humility, a mean calculation is performed. Based on this category, it will be seen the level of cultural humility of students in general and cultural humility on each of the factors. The cultural dynamic personality humility of each participant was enriched by in-depth interviews, shortly after the participant filled out the research instrument.

\section{RESULTS AND DISCUSSION}

Based on the results of the study using the Cultural Humility Scale (CHS), information was obtained that from the three students, two students were in the category of moderate cultural humility, and one student was in the category of high cultural humility. The following is a more detailed explanation from each student regarding the dynamics of his personality related to his ability in terms of cultural humility.

In the first student, NAH, a CHS score of 43 was obtained. The score was in the medium category. There are several interesting things related to the dynamics of the personality of NAH, which is the female sex. Based on the results of in-depth interviews with $\mathrm{NAH}$, information is obtained that $\mathrm{NAH}$ has 
an interpersonal personality that is more dominant than an intrapersonal personality. This can be known from their daily activities. Aside from being a student in the Islamic Guidance and Counseling department, NAH is active in community activities as a member of the Village apparatus. NAH prioritizes how to interact well with people around her, rather than focusing on herself.

These findings are as stated by Davis, Worthington, and Hook (2010), which defines humility generally includes intrapersonal and interpersonal components. On the intrapersonal dimension, humble individuals have an accurate view of themselves. On the interpersonal dimension, humble individuals can maintain interpersonal attitudes that are oriented more towards others than focusing on themselves, characterized by respect for others. Between these two focuses, the interpersonal dimension is potentially more relevant to the guidance and counseling relationship and can be more accurately felt by the counselee. (Hook, Davis, Owen, Worthington \& Utsey, 2013).

NAH has an interpersonal dimension that is more dominant than the intrapersonal dimension. This has implications for cultural humility owned by $\mathrm{NAH}$ in the medium category. Cultural humility reflects an attitude towards others, which is characterized by openness, curiosity, lack of arrogance, and a sincere desire to understand the cultural identity of the counselee. Counselors with a high level of Cultural Humility rarely consider their competence, but rather approach the counselee with respectful openness and collaboratively explore the cultural identity of the counselee. (Owen, Tao, Drinane, Hook, Davis, \& Kune, 2015).

$\mathrm{n}$ the second student, ANU, a CHS score of 40 was obtained. When viewed from the acquisition of the score, the male student entered into the category of moderate cultural humility. Based on the results of interviews conducted, information was obtained that ANU was included as an active student in the organization. This activity makes ANU always interact with other people who have different cultural backgrounds from her. Through these activities, ANU explained that most likely, this is what caused ANU to have the ability to interact well with the people around her, so they have moderate cultural humility

In a multicultural context, cultural humility is a process of openness, selfawareness, combining self-reflection and criticism after interacting with culturally diverse individuals. The results of achieving cultural humility are 
mutual empowerment, respect, partnerships, optimal care, and lifelong learning (Tinkler \& Tinkler, 2016). Specifically, cultural humility is an important aspect in multicultural contexts that involves the ability to maintain interpersonal attitudes that are oriented to others (or open to others) about aspects of cultural identity that are most important to clients (Hook, Farrell, Davis, DeBlaere, Tongeren, \& Utsey, 2016). ANU has good cultural humility as a result of its interaction processes with people who have diverse cultural backgrounds.

In the third student, EHA, a CHS score of 56 was obtained. The score indicated that this female student entered the high cultural humility category. Information obtained about the dynamics of his personality, that the EHA has good experience, especially in terms of critical thinking. This experience was gained after EHA was active as a student. The experience was in the form of learning styles during EHA attending lectures both inside and outside the classroom. Through his learning style, which is the impact of experiential learning from his past, EHA can foster good self-awareness.

It was stated by Vesely, Brown \& Mehta (2017) that experiential learning has a big influence on the development of cultural humility, especially in terms of making counselees critically ponder, think and act. This understanding recognizes the importance of experience to critically reflect a person's attitudes and assumptions to think and act new. This learning serves as a vehicle to foster cultural humility because it is an ongoing process of self-awareness, critical reflection, and a shift in attitude. Through this learning can develop the ability of individuals to focus on changes in themselves as they interact with others. EHA managed to utilize this experience to foster cultural humility which is an ongoing process in life.

\section{CONCLUSION}

The results of the study indicate that the cultural humility profile of each student cannot be separated from his activities or activities in daily life. This shows that cultural humility is an ability that is not necessarily owned automatically by individuals. A special development program is needed so that cultural humility can be well mastered by prospective counselors. One of them is the humility counseling development program as explained earlier. Through this guidance program, it is hoped that it can foster cultural humility, which in the end can be obtained from the endpoint of cultural humility in the form of the character of flexibility or humility from individuals when interacting with others. 


\section{REFERENCE}

Barbarino, M. L., \& Stürmer, S. (2016). Different origins of xenophile and xenophobic orientations in human personality structure: A theoretical perspective and some preliminary findings. Journal of Social Issues, 72, 432-449. http://dx.doi.org/10.1111/josi.12175(link is external)

Borkan, J.M. et. al. (2008). Towards Cultural Humility in Healthcare for Culturally Diverse Rhode Island. Medicine and Health: Rhode Island. Vol. 91, No. 12.

Davis, Don E., DeBlaere, Cirleen, Brubaker, Kacy, Owen, Jesse, Jordan II, Terrence A., Hook, Joshua N., \& Tongeren, Daryl R. Van. (2016). Microaggressions and Perceptions of Cultural Humility in Counseling. Journal of Counseling \& Development, 94. 483-493.

Hook, J. N., Davis, D. E., Owen, J., Worthington Jr, E. L., \& Utsey, S. O. (2013). Cultural humility: Measuring openness to culturally diverse clients. Journal of Counseling Psychology, 60, 353-366. doi:10.1037/a0032595

Hook, Joshua N., Farrell, Jennifer E., Davis, Don E., DeBlaere, Cirleen, Tongeren, Daryl R. Van, \& Utsey, Shawn O. (2016). Cultural Humility and Racial Microaggressions in Counseling. Journal of Counseling Psychology, 63 (3), 269-277.

Levi, Amy. (2009). The Ethics of Nursing Student International Clinical Experiences. Journal of Obstetric, Gynecologic, and Neonatal Nursing. Vol. 38, No. 1, pp. 94-99.

Marsella, A. J. (2011). The United States of America: A culture of war. International Journal of Intercultural Relations, 35, 714728. http://dx.doi.org/10.1016/j.ijintrel.2011.09.007

Miller, Suellen. (2009). Cultural Humility is the First Step to Becoming Global Care Providers. Journal of Obstetric, Gynecologic, and Neonatal Nursing. Vol. 38, No. 1, pp 92-93.

Mufrihah, Arina. (2014). Implikasi Prinsip Bimbingan dan Konseling terhadap Kompetensi Multikultural Konselor. Jurnal Pelopor Pendidikan, 7 (1).73-85. 
Owen, J. (2013). Early career perspectives on psychotherapy research and practice: Psychotherapist effects, multicultural orientation, and couple interventions. Psychotherapy, 50, 496-502. http://dx.doi.org/10.1037/a0034617.

Owen, J., Tao, K. W., Drinane, J. M., Hook, J., Davis, D. E., \& Kune, N. F. (2015). Client Perceptions of Therapists' Multicultural Orientation: Cultural (Missed) Opportunities and Cultural Humility. Professional Psychology: Research and Practice. http://dx.doi.org/10.1037/pro0000046.

Pinto, A.D., Upshur, R.E.G. (2007). Global Health Ethics For Students: Developing World Bioethics. Blackwell Publishing Ltd.

Ross, Laurie. (2010). Notes From the Field: Learning Cultural Humility Through Critical Incidents and Central Challenges in Community-Based Participatory Research. Journal of Community Practice, 18:2-3. 315-335. DOI: 10.1080/10705422.2010.490161.

Sanyata, Sigit. (2013). Paradigma Bimbingan dan Konseling: Pergeseran Orientasi dari Terapeutik-Klinis ke Preventif-Perkembangan. Paradigma, 7 (15). 95-114.

Setyaputri, Nora Yuniar. (2017). Karakter Ideal Konselor Multibudaya Berdasarkan Nilai Luhur Semar. Jurnal Kajian Bimbingan dan Konseling, 2(2), 58-65.

Supriatna, Mamat. (2014). Konteks Budaya dalam Bimbingan dan Konseling. Supriatna, Mamat (Editor). Bimbingan dan Konseling Berbasis Kompetensi: Orientasi Dasar Pengembangan Profesi Konselor. Jakarta: Rajawali Pers.

Tangney J.P. (2000). "Humility: Theoretical perspectives, empirical findings and directions for future research" Journal of Social and Clinical Psychology. Vol 19, pp.70-82.

Tervalon, M., \& Murray-Garcia, J. (1998). Cultural humility versus cultural competence: A critical distinction in defining physician training outcomes in multicultural education. Journal of Health Care for the Poor and Undeserved, 9, 117-125. 
Tinkler, Alan S. \& Tinkler, Barri. (2016). Enhancing Cultural Humility Through Critical Service-Learning in Teacher Preparation, Multicultural Perspectives, 18:4, 192-201, DOI: 10.1080/15210960.2016.1222282.

Vesely, Colleen K., Brown, Elizabeth Levine \& Mehta, Swati. (2017). Developing cultural humility through experiential learning: How home visits transform early childhood preservice educators' attitudes for engaging families, Journal of Early Childhood Teacher Education, 38:3, 242-258, DOI: 10.1080/10901027.2017.1345805.

Wear, Delese. (2008). "On Outcomes and Humility" Academic Medicine, vol. 83 , no. 7, pp. 625-626.

Yeager, Katherine A., \& Bauer-Wu, Susan. (2013). Cultural humility: Essential foundation for clinical researchers. Appl Nurs Res, 26 (4). doi:10.1016/j.apnr.2013.06.008. 